\title{
Glycerol kinase deficiency, infantile form
}

INSERM

\section{Source}

INSERM. (1999). Orphanet: an online rare disease and orphan drug data base. Glycerol kinase deficiency, infantile form. ORPHA:284408

Infantile glycerol kinase deficiency (GKD) is a severe form of GKD (see this term) characterized clinically by poor feeding, failure to thrive, salt-wasting dehydration, vomiting, Addisonian pigmentation, hypotonia, and disorders of consciousness. Some patients have complex GKD associated with adrenal hypoplasia cong enita and/or Duchenne muscular dystrophy (DMD) (see these terms) with manifestations including intellectual deficit, dysmorphic facial features, abnormal external genitalia, strabismus, seizures, and progressive lethargy. 